\title{
Análisis descriptivo de narraciones escritas por niños y niñas de tercer año básico*
}

\author{
Ricardo Benítez Figari**
}

\section{Resumen}

Se aplicó una escala holística focalizada a la producción de textos narrativos escritos por 165 estudiantes de tercer año básico, como uno de tres instrumentos utilizados en una investigación mayor (Proyecto FONDECYT No 1070333). La escala permitió clasificar la producción de dichos textos en seis tipos según el puntaje otorgado por tres evaluadores. Ninguno de los textos obtuvo los dos puntajes máximos y se observa tanto una marcada influencia de la oralidad como una limitada utilización del discurso descriptivo.

Palabras clave: escala holística, puntaje del rasgo primario, escala holística focalizada, evaluación de la producción escrita, perfil del escritor.

\section{Abstract}

A focused holistic scale, as one of three instruments employed in a more extensive investigation (FONDECYT Project № 1070333), was applied to the production of narrations written by 165 third graders. This scale helped classify the production of such texts according to the scores given by three raters. None of the texts received the two highest scores, and a strong influence of orality as well as a limited use of description was observed.

Key words: holistic scale, primary trait scoring, focused holistic scoring, writing assessment, writer's profile.

* Master en la Enseñanza del Inglés como Segunda Lengua, Arizona State University, Estados Unidos. Profesor de Producción Escrita en Inglés. Académico Instituto de Literatura y Ciencias del Lenguaje Pontificia Universidad Católica de Valparaíso.

rbenitez@ucv.cl 


\section{Introducción}

La utilización de una escala holística focalizada (EHF) que se aplicó para evaluar la producción de textos escritos por niños y niñas que cursaban tercer año básico arrojó resultados que merecen la atención de los profesores que dictan dicho nivel de escolaridad. Estos estudiantes fueron los participantes en una investigación de mayor alcance ${ }^{1}$, cuyos objetivos son, por un lado, detectar habilidades metalingüísticas y/o cognitivas que pudieran asociarse al desarrollo de la comprensión oral del lenguaje no literal en la edad escolar y, por otro, detectar la existencia de diferencias sistemáticas en el desarrollo tanto de la lectura como de la escritura en niños y niñas con variados niveles de comprensión de lo no literal.

Lo anterior permitirá discriminar entre buenos y malos comprendedores del lenguaje figurativo y de lo textual escrito como también entre buenos y malos productores de textos escritos. Dicho proyecto tiene carácter interuniversitario, ya que la Universidad de La Serena colabora en ella, en particular con investigadores expertos en comprensión de lectura.

Una de las cosas más difíciles en la labor del profesor de Lenguaje y Comunicación es la evaluación de textos escritos por sus estudiantes, en particular cuando se intenta entregar a las composiciones una evaluación lo más objetiva posible. Sabemos que esto es un ideal en la evaluación de la producción escrita, puesto que para transparentar objetividad se necesitaría de un consenso evaluativo entre pares evaluadores. Si bien es cierto lo anterior bien podría llevarse a cabo en nuestras escuelas, la realidad nos dice otra cosa: falta de tiempo, tedio de corregir tantas composiciones, cansancio de leer errores (y algunos inclasificables), sensación de que nuestros estudiantes no aprenden lo que se les enseña, etc. La propuesta de utilizar una escala que contiene rúbricas es una de las

$1 \quad$ Proyecto FONDECYT No 1070333. 
alternativas que tenemos los profesores de composición escrita para dar un carácter menos subjetivo a las composiciones que escriben nuestros estudiantes, aunque persiste el hecho de poder -y tener que- lograr consenso entre pares evaluadores para validar dicha escala. Generalmente, dichos evaluadores no son los profesores de esos estudiantes cuyas composiciones escritas se deben leer y corregir, a lo cual se añade otro problema: encontrar profesores que estén dispuestos a colaborar entre ellos y que dispongan del tiempo para llevar a cabo en forma efectiva dicha tarea. Lo anterior se hace tremendamente difícil, puesto que el hecho de leer composiciones de estudiantes que no son los propios conlleva una considerable carga horaria para esos pares evaluadores.

Se realizó un piloteo de la EHF con 165 estudiantes de escuelas municipales y subvencionadas de la Quinta Región, en particular de las ciudades de Valparaíso y Viña del Mar, y su objetivo fue el de lograr consenso entre al menos tres jueces evaluadores. La aplicación de esta escala, cuyos detalles se verán más adelante, permitirán afinarla con el propósito de utilizarla en una muestra que contempla la participación de 400 niños y niñas con el mismo nivel de escolaridad -tercer año básico-en establecimientos educacionales ubicados en las mismas ciudades antes mencionadas, esta vez incluyendo la ciudad de La Serena. Estos 400 niños y niñas conformarán el universo de la investigación mayor ya aludida.

El objetivo del presente trabajo es, por un lado, presentar los resultados preliminares arrojados por el piloteo de la aplicación de dicha escala, considerando que ésta es sólo uno de los instrumentos que se emplearán en la investigación mayor; por otro, describir la producción escrita narrativa de este segmento de la población estudiantil; y por último, sugerir la utilización de una escala holística focalizada para la evaluación de narraciones escrita.

\section{La EHF y otras evaluaciones}

Antes de presentar los resultados de la aplicación de la escala, es necesario diferenciarla con al menos otras dos cuyo empleo es más o menos generalizado en la evaluación de composiciones escritas: la holística pura o simple y el puntaje de rasgo primario. Con la primera, el evaluador clasifica las composiciones de acuerdo al resto de las composiciones entregadas por los estudiantes de un mismo curso y se asignan puntajes a ciertos rasgos que el evaluador considera relevantes al tipo de texto que se ha solicitado con la ayuda de una pauta que describe cada uno de esos rasgos, identificando, de esta manera, niveles de calidad alta, media y baja (Weigle, 2002). Con la segunda -puntaje del rasgo primario- el evaluador establece algunas características del discurso que ha solicitado 
a los estudiantes en una tarea y penaliza severamente el incumplimiento de las instrucciones para llevarla a cabo, sin considerar lo efectivo o lo estilizado del discurso utilizado. La filosofía detrás del puntaje de rasgo primario es que es importante entender cuán bien los estudiantes escriben en un espectro del discurso que se haya acotado dentro de ciertos límites (por ejemplo, persuasión o explicación) (Weigle, 2002).

Según Weigle (2002), tanto las escalas holísticas como las de puntaje de rasgo primario poseen ventajas y desventajas en forma diferenciada. Entre las desventajas del uso de una escala holística se encuentra que ésta no proporciona información diagnóstica útil acerca de la habilidad para escribir, ya que un puntaje único no permite a los evaluadores distinguir entre diversos aspectos de la escritura, tales como el control de la sintaxis, la profundidad del vocabulario, la organización, y así sucesivamente; además, este tipo de escalas no siempre son fáciles de interpretar, puesto que los evaluadores no necesariamente utilizan los mismos criterios para llegar a los mismos puntajes. Entre las desventajas del puntaje de rasgo primario se encuentra que éste es bastante detallado y bastante específico en términos de las diferencias con las cuales los escritores emprenden la tarea de escritura, razón por la cual toma también bastante tiempo y trabajo elaborar una escala de este tipo, considerando que se debe diseñar una para cada tipo de tarea.

En cambio, la EHF es una fusión de las dos anteriores (White \& Venneman, 1999): combina el trabajo de clasificar las composiciones en forma seriada o graduada entre bajas, medias y altas (según su calidad para su evaluación) con rasgos que se consideran importantes en la producción de determinado tipo de texto. Es decir, el evaluador -además de emitir un juicio sobre la calidad de las composiciones-, utiliza una rúbrica que le permite clasificarlas de acuerdo a los criterios determinados en esa rúbrica. La evaluación holística simple exige que el evaluador comparta con otros evaluadores los mismos criterios de calidad para clasificar las composiciones y requiere de lectores expertos; por tal razón, es necesario que se capacite a esos otros evaluadores en el establecimiento de qué se entenderá como calidad buena, media y alta.

Por el contrario, el puntaje del rasgo primario es un instrumento evaluativo que exige la acción de un solo evaluador (juez o lector) y éste se guía por una pauta previamente diseñada con las características que él busca en las composiciones. Por ejemplo, el programa del curso puede exigir el conocimiento de los tres principales componentes de la situación retórica de una composición escrita -tópico, audiencia y propósito-y el evaluador puede centrarse en la evaluación de cuán efectivamente estos componentes se manifiestan; el evaluador, por otro lado, puede focalizar su atención en el uso del pasado gramatical en un texto narrativo o en 
cuán exitoso ha sido el uso de la coordinación y de la subordinación en la construcción de párrafos. Para calificar una composición, entonces, el evaluador sólo presta atención a esos aspectos y en ningún otro que esté presente en un tipo de texto determinado.

Como se dijo anteriormente, la EHF combina estos dos tipos de evaluación. Por un lado, permite clasificar los textos escritos de acuerdo a su calidad y, por otro, permite fijar la atención en ciertas características que exige la tarea de escritura, en este caso particular, la construcción de un texto narrativo.

LA EHF, además, es un instrumento que se ajusta en forma satisfactoria a la producción de textos narrativos, porque permite incorporar tanto los diversos elementos que componen una narración (por ejemplo, el desarrollo de una trama, la evolución de los personajes, el uso coherente de un marco temporal referencial, la presencia de un tema y de un contexto) como la manera en que se ha desarrollado la comunicación (por ejemplo, la consideración de la audiencia, que por lo general se manifestará con el uso de un registro lingüístico apropiado).

El presente trabajo presenta la EHF como un instrumento que permitió evaluar las composiciones de niños y niñas de tercer año básico de acuerdo a seis clases de respuestas ${ }^{2}$ a la exigencia que presentaba la tarea que debían realizar: Respuesta Insatisfactoria, Insuficiente, Desequilibrada, Suficiente, Idónea o Excelente (ver Anexo 1). La EHF en realidad es una rúbrica que contiene descriptores por cada una de las posibles respuestas, las cuales -una vez que finalice el análisis de las composiciones escritas por los 400 estudiantes-, se harán relacionar con cuatro descriptores de tipos de productores: Novicio, Aprendiz, Competente y Distinguido, según la taxonomía de Spalding \& Cummins (1998) (Ver Anexo 2).

Si bien históricamente los evaluadores han encontrado una inmensa ayuda en las rúbricas para complementar su labor, éstas también deberían utilizarse como importantes herramientas para la enseñanza de la producción escrita cuando en una primera instancia se les presentan a los estudiantes y después cuando el instructor se refiere a ellas durante el proceso de evaluación de las composiciones. Aquí, obviamente, se está presuponiendo que el evaluador y el instructor son la misma persona; sin embargo, eventuales evaluadores pares pueden colaborar con la enseñanza de la composición escrita a través de la retroalimentación que entreguen a los profesores de los estudiantes que han escrito dichas composiciones.

2 "Respuesta" se denomina el texto que se produce como resultado de una tarea de escritura o exigencia. 
Hamps-Lyons (1991), por ejemplo, sostiene que cualquier método de evaluación de la escritura que deja de utilizar el potencial educativo del instrumento permite que haya una ruptura entre la enseñanza y la evaluación. Se puede emplear una rúbrica en forma efectiva como una herramienta para la enseñanza cuando se presenta a los estudiantes los primeros días de clase y cuando a los estudiantes-escritores se les ofrecen oportunidades de trabajar con ella antes de que sus criterios se apliquen a las evaluaciones de sus propios textos en proceso o a sus productos finales. Además, las rúbricas bien diseñadas pueden funcionar como un marco consistente para proporcionar retroalimentación significativa para los estudiantes, de modo tal que éstos la usen para revisar $y$, de este modo, mejorar sus composiciones. Sin embargo, para que sea usada productivamente de esta manera, los descriptores deben ser explícitos, comprensibles y orientados específicamente tanto hacia los niveles de competencia de los estudiantes como a los focos retóricos del curso (Ferris \& Hedgcock, 1998).

\section{Metodología}

La descripción del instrumento y los resultados obtenidos tras su aplicación corresponde a una fase preliminar de la Prueba de Producción Escrita que se realizará más adelante en la investigación. Esta prueba se administró a un total de 165 estudiantes (92 niños; 70 niñas; 3 sin información) que cursaban el tercero básico en colegios municipalizados y subvencionados de la Región de Valparaíso.

Para llevar a efecto el piloteo mencionado más arriba, se entrenó a ayudantes que colaboran en la investigación mayor para que administraran la tarea de escritura en las escuelas. Se enfatizó que todos los ayudantes debían dar las mismas instrucciones, en lo posible utilizando las mismas palabras, si bien los participantes contaban con instrucciones escritas para el desarrollo de la composición (Ver Anexo 3). A los participantes se les dio sugerencias en forma de tópicos como fuentes de inspiración, con el fin de evitar la pérdida de tiempo, ya que se contaba con sólo una hora de clases para la realización de la tarea. Dichas sugerencias fueron seleccionadas de los tópicos recurrentes que aparecen en un libro patrocinado por el Ministerio de Educación y el Grupo Océano de Chile (Pastor \& Carvani, s.f.), el cual recoge composiciones narrativas escritas por estudiantes de tercero a octavo básico. Evidentemente, los tópicos seleccionados de dicho libro para esta ocasión fueron los más recurrentes en las composiciones de los estudiantes de tercero básico. Los participantes también pudieron inspirarse en imágenes que se mostraron en una pantalla (como en una presentación power point). 
Los participantes contaron con dos hojas en blanco que les fueron proporcionadas por los ayudantes de la investigación. La idea de entregarles estas dos hojas era que una de ellas la utilizaran para escribir un borrador con el fin de observar en los participantes que en el proceso de componer por escrito, la revisión es un proceso esencial.

La lectura de las composiciones estuvo a cargo de tres jueces pares, los cuales evaluaron el desempeño de los participantes de acuerdo a la pauta de corrección con rúbricas, clasificando así sus composiciones de la forma descrita anteriormente.

Para la validación del instrumento -la escala holística focalizada- se utilizó una análisis de varianza (ANOVA) de un factor efectos fijos (orientado a constatar que existían diferencias significativas en los puntajes medios asignados por los jueces), y el coeficiente de correlación de Pearson (orientado a estimar el nivel de asociación lineal existente entre los jueces). Las pruebas estadísticas arrojaron como resultado que no existen diferencias significativas en los puntajes asignados por los distintos jueces $y$, por consiguiente, se puede asegurar la validez del instrumento, debido a que la variabilidad entre jueces es despreciable (Montenegro \& Pérez, 2008). Con la aplicación del test de correlación de Pearson se encontró que entre los puntajes asignados por los jueces existe asociación lineal directa entre los puntajes, siendo mayor entre los jueces 1 y $3(r=0.78)$. La siguiente Tabla muestra estos resultados:

TABLA 1: Coeficiente de Correlación de Pearson entre Jueces

\begin{tabular}{|c|c|c|c|}
\hline $\begin{array}{c}\text { Coeficiente } \\
\text { Correlación }\end{array}$ & R & D & P \\
\hline R & 1 & & \\
\hline D & 0,59 & 1 & \\
\hline P & 0,78 & 0,64 & 1 \\
\hline
\end{tabular}

Se utilizará el mismo método anteriormente descrito una vez que se emprenda la administración de la tarea de escritura que será evaluada con esta misma escala para efectos de análisis en la investigación mayor y que comprenderá el universo de 400 estudiantes ya mencionado. 


\section{Resultados}

Como se señaló en la introducción, los resultados obtenidos después de la aplicación de la EHF a los productos escritos por los participantes no son muy alentadores, si bien la gran mayoría de los textos está acorde con una superestructura narrativa. En primer lugar $-\mathrm{y}$ admitiendo que la EHF aplicada requiere de un alto grado cognitivo-, ninguno de ellos obtuvo alguno de los dos primeros puntajes, es decir, 5 ó 6, los cuales corresponden a las respuesta 'idónea' y 'excelente'.

Se observó, además, una ausencia total de lenguaje figurativo. Sus composiciones abundan en lenguaje literal, sin recurso alguno de, por ejemplo, metáforas o ironías ${ }^{3}$. Se podría pensar que estos recursos significan una exigencia demasiado alta en composiciones producidas por niños y niñas de tercero básico; sin embargo, la investigación y la literatura consultada aún no dilucida en qué momento del desarrollo el ser humano inicia la utilización del lenguaje figurativo o de simbolismo como recurso de expresión.

En general, el orden de los eventos presentados en las composiciones no siempre es claro. Se detectaron saltos en la secuencia temporal de los eventos narrados, en particular debido a la falta casi total de conectores que los señalaran. El único conector detectado fue "entonces", marcando con él la transición de un evento a otro. El pasado gramatical se confunde muchas veces con el presente para referirse a un episodio que incluye expresiones textuales que los personajes dicen en el momento en que ocurren los eventos. Lo anterior dificultó la lectura de la trama de la narración al no contar con marcas textuales que ayudaran a hacer esta división entre presente y pasado.

El desarrollo de los personajes es bastante precario, aunque algunas composiciones se preocupan de establecer en forma efectiva quién es el protagonista y quiénes son los personajes secundarios, como también en sólo algunas se detectó la motivación de los personajes para comportarse de esa manera y no de otra. En otras palabras, no se detectó ningún tipo de texto descriptivo (por ejemplo, de personajes o de lugares) que acompañara y apoyara las narraciones

En el ámbito de la coherencia y la cohesión, se observó que los participantes no emplean recursos ni hipotácticos ni paratácticos. La

3 Nos interesaba detectar más que nada el uso de ironías o metáforas por ser éstos los tropos que se han analizado en la investigación mayor y cuya comprensión oral se midió en una investigación anterior (FONDECYT № 1040740) a través del Instrumento de Medición de Inferencias Pragmáticas (IMIP), diseñado especialmente para dicha investigación. 
subordinación de ideas no es parte de los recursos cohesivos a los que recurren y la coordinación de ideas se limita a un excesivo uso de la conjunción " $y$ ". Evidentemente, habría sido una exageración de parte de los lectores-jueces esperar que los participantes hubiesen empleado conjunciones correlativas. Por otro lado, se detectó ausencia de revisión de las composiciones como parte fundamental del proceso de producir por escrito. La mayoría de éstas se entregó con las dos hojas con las que los ayudantes de la investigación proveyeron a los participantes y también la gran mayoría de éstas no presenta borrones ni señales de que ciertas palabras o ideas habían sido borradas con goma, ya que se les exigió que escribieran con lápiz grafito precisamente para que les fuera más fácil la corrección de errores. La revisión de las composiciones por los participantes no era, evidentemente, un requisito para la consecución de la tarea de escritura, sobre todo a causa del tiempo asignado, pero esta parte del análisis deja entrever que, en general, los participantes no poseen prácticas revisoras. Caben dos posibles alternativas aquí: o dichas prácticas no forman parte de los programas de estudio o el tiempo asignado para narrar el cuento fue insuficiente.

Las composiciones en su totalidad presentan múltiples errores de puntuación y ortografía. En la gran mayoría de ellas, se detectó una ausencia de marcas de puntuación y cuando existen, están mal utilizadas o no se corresponden con el pasaje del texto en que fueron ubicadas. La mala ortografía no se consideró tan grave como el mal empleo de las marcas de puntuación, pero frecuentemente ésta impidió le lectura -y por tanto, la evaluación- fluida de las narraciones. No es de extrañar que las composiciones que obtuvieron el mejor puntaje otorgado $(4$, vale decir, Respuesta Suficiente) sean las que presentan mejor puntuación y mejor ortografía.

En otro orden de cosas, el análisis de las composiciones también incluyó la detección de los temas más recurrentes y si éstos fueron tomados de las sugerencias presentadas, ya sea en forma escrita o en forma de imagen. Se sabe también que la narración es el tipo de texto que se aprende con mayor facilidad, tal vez por el hecho de haber sido ejercitada oralmente en repetidas ocasiones. Lo que no se sabe a ciencia cierta es si los niños de este grupo etario pueden mantener el tópico y/o si tienen un propósito claro al narrar. Los temas a los que recurrieron los participantes para desarrollar la tarea se relacionaron con la amistad, el amor, los animales, la ciencia ficción, el horror, la mitología y los programas de televisión, observándose así una clara influencia de los temas sugeridos y/o de las imágenes presentadas. El texto con el tópico relacionado con animales tiene la mayor frecuencia absoluta. La influencia de la festividad del horror, (especialmente su referencia a la festividad de Halloween), se debe, al parecer, a la cercanía con la fecha en que se administró la tarea 
(fines de octubre, principios de noviembre). En todo caso, la recurrencia a esta festividad como tema es parte de una mayor, que se podría adscribir al género del horror. En otras palabras, este género-muy inspirador entre los participantes para el desarrollo de sus composiciones- abarcaría la festividad mencionada. (Con el fin de ser fuentes de inspiración entre los 400 estudiantes que participarán en la investigación mayor, se incluirán los mismos temas seleccionados para el piloteo. De esta manera, se intentará aliviar la carga cognitiva que significa tener que producir por escrito en tan poco tiempo.)

Entre los datos que se les solicitó a los participantes estaban sus identidades sexuales con el fin de analizar los temas preferidos por los niños y los preferidos por las niñas, como también quiénes demuestran mayor habilidad, al menos en esta etapa de su desarrollo, para producir un texto narrativo. Esta porción del análisis reveló que, tal vez sin ser motivo de extrañeza o sorpresa, los niños prefieren las narraciones con un alto contenido de violencia y agresividad, generalmente de programas de televisión cuyos protagonistas son de sexo masculino con un alto grado de fuerza y poder; de hecho, de aquellos participantes que desarrollaron su composición con un tópico relacionado con violencia y acción, el 100\% fue de sexo masculino; en tanto que las niñas demuestran una clara tendencia tanto a los cuentos de animales, cuyas vidas transcurren en una granja, como a los de princesas y príncipes con una relación amorosa entre ellos.

Por otro lado, las niñas obtuvieron una calificación significativamente mejor que los niños, con una nota promedio de 2,2 las primeras y de 1,7 los segundos. El promedio de nota es 1,9 para ambos géneros y una prueba formal (ANOVA) permite verificar que esta diferencia es estadísticamente significativa (p.valor<0.01) (Montenegro \& Pérez, 2008). Sin embargo, cabe señalar, como lo muestra la Figura 1, que ninguno de los participantes -independientemente del género- obtuvo la calificación 5, ni tampoco la calificación de 6 (respuestas idónea y excelente, respectivamente). Asimismo, la calificación 2 (respuesta insuficiente) fue la más frecuente. 
FIGURA 1: Número de participantes según nota y juez

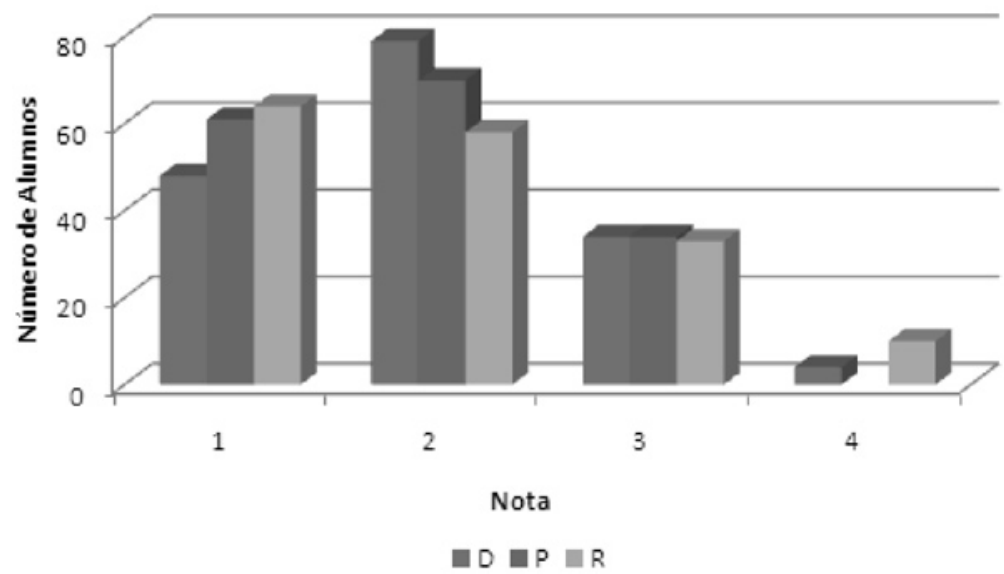

Los participantes no se preocuparon de revisar sus composiciones, pero sí se dedicaron a ilustrarlas con dibujos hechos y coloreados por ellos mismos. Sabemos que los niños de tan corta edad como los que cursan el tercer año básico no tienen conciencia de la audiencia a la cual dirigen sus composiciones escritas, más que nada porque se encuentran en una etapa egocéntrica de su desarrollo. Al parecer, la ilustración es parte fundamental de un buen entendimiento para la comprensión de un cuento y lleva a pensar que los dibujos se utilizan para llenar el vacío que significa la falta de un interlocutor inmediato en la relación entre lector y escritor. Por lo anterior, se podría pensar que estas imágenes visuales compensan, de alguna manera, la carencia de recursos (y registros) lingüísticos adecuados a la tarea.

El 96\% de los participantes titula su composición y el $85 \%$ la inicia con la frase "Había una vez...", confirmando, de alguna manera, la internalización de una superestructura narrativa y la fuerza con la cual la oralidad se ve reflejada en sus productos. Los participantes deben haber escuchado o leído muchas veces "Había una vez..." -como frase introductoria cliché en los cuentos infantiles-, para que dicho porcentaje la incluyera como introducción a sus narraciones.

Por último, el análisis de las composiciones permitió detectar el evidente sentido del bien y del mal que poseen los participantes. Las composiciones en su totalidad presentan personajes buenos que son considerados como héroes y heroínas, como también personajes malos que son considerados los villanos de los cuentos. En el caso de faltar un personaje cuyas acciones podrían ser reprochables, el estudiante-escritor, participante de esta investigación, ensalza las virtudes de los personajes buenos. En otras palabras, en sus composiciones no existen los personajes ambiguos o difíciles de interpretar como buenos o malos. Los niños y 
niñas dan a entender que en esta etapa de su desarrollo saben muy bien qué tipo de acciones humanas se pueden considerar virtudes o vicios.

\section{Conclusiones}

Los poco alentadores resultados arrojados por el análisis de las composiciones escritas por estudiantes de tercer año básico merecen comentarios como los que se detallan a continuación. Es verdad que la escala empleada puede haber sido demasiado exigente para el nivel de escolaridad de los participantes, ya que ninguno de ellos obtuvo el puntaje 5 o el puntaje 6 . Sin embargo, también es cierto que los programas de estudio para ese nivel carezcan de algunos aspectos contemplados en la escala sugerida aquí. El puntaje 6 de la rúbrica afina descriptores que ya el puntaje 1 incluye. Por ejemplo, la organización de los eventos "siempre es claro, incluso en el pasado o en el futuro". O en cuanto a los personajes, éstos son "pulidos y dinámicos a través de la descripción rica en afecto, intención y motivación". Lo anterior lleva a pensar que o los objetivos de dicho programa aparecen reducidos o que los profesores no requieren de sus estudiantes mayores afinaciones en sus productos escritos.

Otro de los aspectos que se debiera tomar en cuenta es la limitada utilización del discurso descriptivo para acompañar al narrativo. El primero se considera como un tipo de texto en sí mismo para, posteriormente, incluirlo en otros tipos de textos, en particular el narrativo y el expositivo $y$, en algunos casos, el argumentativo. En la realidad, los textos descriptivos puros son escasos. Al analizar las composiciones, la descripción, ya sea de personajes o de lugares, raras veces apoya la narración y es posible aventurar, entonces, que se ignore en las clases de Lenguaje y Comunicación. Lo anterior también puede ser el reflejo de una falta de lectura detallada entre los participantes o de instrucciones poco claras y explícitas de parte de los profesores.

Las composiciones, además, reflejan que los participantes vierten en sus composiciones su manejo del código oral, típico de la etapa de su desarrollo. A través del registro lingüístico detectado, la mayoría de ellas revela desconsideración con la audiencia, haciendo el discurso inmediato entre ellos y sus lectores. Sin embargo, el propósito de sus productos escritos está claro: narrar un cuento cuya superestructura es apropiada.

Hace bastante tiempo que las marcas de puntuación, no tanto así la ortografía, se consideran elementos clave para el entendimiento entre escritor y lector. Éstas llevan una carga semántica que muchas veces se ignora, porque la tradición de verlas como parte de la mecánica o de la 
cosmética de la escritura ha pesado bastante. Sin embargo, las marcas de puntuación son marcas también de significación que colaboran en la comprensión de los textos escritos. Por consiguiente, se debería instruir a los estudiantes en su correcta utilización como base para una efectiva expresión y parte de la semántica de lo producido.

Si no es por un poco frecuente uso de la hipérbole, el empleo del lenguaje figurativo en las composiciones estudiadas equivale a cero. No está claro cuándo los niños y niñas comienzan a usar el lenguaje no literal, pero lo que muestran las composiciones una vez analizadas es que no se estimula su uso, tal vez porque los programas de producción escrita no lo integran. Lo anterior induce a reflexionar sobre la importancia de desarrollar, fomentar y mantener la creatividad en los niños a medida que avanzan en su desarrollo. Esta creatividad bien puede empezar con el uso del lenguaje.

Todo lo anterior permite llegar a la conclusión de que habría que incluir prácticas revisoras en las clases de composición como parte esencial del proceso de producir por escrito. Se debería instituir una cultura de la revisión en nuestras escuelas que ayudaría a retroalimentar nuestras metodologías. El mismo hecho de anunciar en la sala de clase que se aplicará una escala holística focalizada,-como la validada para este estudio-, familiarizando a los estudiantes con sus respectivos descriptores para futuras evaluaciones, ayudaría a poner en marcha dicha retroalimentación y transformaría la imagen de tedio que se tiene de la corrección de composiciones entre los docentes de esta área del lenguaje.

En todo caso, los resultados presentados aquí son preliminares y se tendrá que ver qué resultados se obtiene -una vez que la EHF se aplique a las 400 composiciones que conformarán el corpus de la investigación mayor-, en una versión que mostrará modificaciones en cuanto a la agrupación de los descriptores que la conforman.

\section{Bibliografía}

Ferris, D. \& Hedgcock, J. S., (1998). Teaching ESL composition: Purpose, process and practice. Mahwah, NJ: Lawrence Erlbaum Associates.

Hamps-Lyons, L. (1991) Assessing second language writing in academic contexts. Norwood, NJ.: Ablex.

Montenegro, C. y Pérez, L., (2008). Análisis estadístico. Prueba de producción escrita. Informe no publicado para el Proyecto FONDECYT № 1070333. 
Pastor, E. y Carvani, G. (s.f.). (Cords.). Historias de Grandes Pequeños. Santiago: Fe\&Ser Ltda.

Spalding, E \& Cummins, G. (1998). "It was the best of times. It was a waste of time: University of Kentucky students' view of writing under KERA". Assessing Writing 5 (2), 167-199.

Weigle, S. (2002). Assessing writing. Cambridge: Cambridge University Pres.

White, S. \& Venneman, A. (2000). "NAEP scoring of fourth-grade narrative writing”. En The National Center for Educational Statistics. NAEP Facts, (1), 5 [en línea]. Disponible en:http:// nces.ed.gov/pubs2000/2000495.PDF 


\section{Anexo 1}

\section{Respuesta insatisfactoria}

- El texto no desarrolla una historia (cuento) o es demasiado difícil de entender en todo el texto, proporcionando un mínimo de apoyo o nada de apoyo; puede que sólo haya parafraseado las instrucciones.

- El texto muestra muy poca organización o ninguna.

- El texto no presenta ningún control sobre límites y estructura oracionales; elección léxica puede ser inexacta, limitada e inmadura en la mayor parte del texto; las oraciones son cortas y simples en estructuras o repetitivas.

- El texto presenta errores ortográficos y de puntuación que impiden severamente la comprensión.

- El autor no es un observador ni un participante en forma sistemática.

- El personaje central no es una persona viva real; sólo es un nombre en la página.

- La acción transcurre sin ningún escenario (contexto) detallado; la acción no se puede ver en un lugar determinado. Contexto con muy poca o ninguna indicación de tiempo o lugar ("Había una niña. Le gustaban los dulces".)

- La escritura ligada al contexto y a menudo depende del dibujo y de la conversación para clarificar el significado

- No se entiende qué eventos van primero o después de otros eventos; uno o dos eventos con muy poco o ningún conflicto ("Una vez había un gato. Al gato le gustaba la leche").

- Uno o dos personajes planos y estáticos, con poca relación entre ellos.

\section{Respuesta Insuficiente}

- El cuento es desorganizado o poco centrado o claro; muy breve.

- Control mínimo sobre límites oracionales y estructuras oracionales; la elección léxica a menudo puede ser inexacta.

- Errores en gramática, ortografía y puntuación interfieren con la comprensión en la mayor parte del texto. 
- $\quad$ Producción de sólo el comienzo de un cuento.

- Introduce un personaje nuevo, pero no lo desarrolla más allá de ese punto.

- $\quad$ Alguna clase de pulimento en la descripción física generalmente; la relación entre los personajes está dada por la acción.

\section{Respuesta Desequilibrada}

- Puede faltar desarrollo en partes del cuento o ser repetitivo, o sólo es un comienzo bien escrito.

- Es organizada en partes; otras partes están desarticuladas y/o le faltan transiciones.

- Muestra un control disparejo sobre límites oracionales y estructuras oracionales; puede mostrar elecciones léxicas inexactas; palabras comunes y ordinarias se usan de manera tradicional; contiene expresiones trilladas y exageradas.

- Errores en gramática, ortografía y puntuación interfieren a veces con la comprensión.

- Si existe acción dramática, ésta es repetitiva, ya que los eventos no están conectados para formar un cuento coherente.

- A veces el contexto parece vívido y real, pero a veces la acción sólo pasa y el lector no se da cuenta de cuál es el contexto realmente.

- A veces no está claro qué evento sucedió primero.

- Pulimento continuado de la descripción física, en particular características estereotípicas (verruga en la nariz).

- Inicio de relación entre contexto y otros elementos narrativos (contextos futurísticos para introducir alienígenas y nave espacial).

- Episodio único y lineal con un claro comienzo, medio y fin; el episodio contiene un problema, respuesta emocional, acción y resultado.

\section{Respuesta Suficiente}

- Cuento organizado y claro, con cierto desarrollo.

- Generalmente, es organizada, pero tiene pocas o ninguna transición entre las partes.

- La estructura oracional puede ser simple y poco variada; generalmente, la elección léxica es la apropiada; palabras seleccionadas más cuidadosamente para ajustarse a los propósitos de la narrativa. 
- Los errores en gramática, ortografía y puntuación no interfieren con la comprensión.

- Motivaciones e intenciones que impulsan los sentimientos y acciones de los personajes principales a menudo a través de un punto de vista omnisciente limitado.

- El contexto se vuelve más esencial al desarrollo del cuento de modo explícito: los personajes pueden hacer notar el contexto o el tiempo y lugar puede ser parte esencial a la trama.

- La trama aumenta en complejidad con más de un episodio; cada episodio contiene un problema, respuesta emocional, acción y resultado.

- Información ampliada y explicaciones para el lector (vinculando ideas como también episodios).

- Muestra algo de variedad en la estructura oracional y elige bien el léxico; ocasionalmente, las palabras pueden usarse en forma errónea.

- Los errores en gramática, ortografía y puntuación no interfieren con la comprensión.

- La trama cambia abruptamente en ocasiones.

\section{Respuesta Idónea}

- Apoya el cuento con razones pertinentes y/o ejemplos en la mayor parte del texto.

- Está bien organizada, pero le faltan transiciones.

- Uso de temas secundarios, a menudo vinculados a la trama mayor, pero a veces tangenciales.

- Más pulimento en sentimientos y motivaciones; aparecen características dinámicas en los personajes centrales y entre personajes.

- El contexto puede servir más de una función y la relación entre funciones es más implícita y simbólica.

- Relaciones más fuertes entre episodios, con resolución en uno de ellos que conduce a un problema en el siguiente.

- Algo de experimentación con simbolismo (en particular, el lenguaje figurativo) que demuestra consideraciones hacia el lector. 


\section{Respuesta Excelente}

- El cuento se apoya en forma sistemática con razones y/o ejemplos bien elegidos; puede que use estrategias persuasivas para transmitir argumentos.

- Está focalizado y bien organizado, con un uso efectivo de transiciones.

- En forma consistente, demuestra una variedad en la estructura oracional y precisión en la elección léxica; las palabras se emplean de modo único e interesante; el autor parece reflexivo e imaginativo, aunque en partes el lenguaje utilizado sea inapropiado.

- Los errores en gramática, ortografía y puntuación son pocos y no interfieren con la comprensión.

- El autor mantiene su papel de participante y observador a través de todo el texto.

- La figura central se describe en detalle.

- La acción transcurre en un lugar bien detallado.

- El orden de eventos siempre es claro, incluso en el pasado o en el futuro.

- La trama principal es múltiple y complejo; los temas secundarios se relacionan de forma integral a los temas primarios.

- Personajes principales pulidos y dinámicos a través de la descripción rica en afecto, intención y motivación.

- El contexto se integra completamente con los personajes, acción y trama.

- Problema principal y resolución apoyados por episodios múltiples.

- Cuidadosa elección de estructura narrativa como también el vocabulario demuestra articulación razonable de todos los recursos. 


\section{Anexo 2 \\ Perfil del Escritor (Spalding \& Cummins, 1998)}

\section{Novicio}

- Conciencia de audiencia y propósitos limitada

- Idea de desarrollo mínima; detalles limitados y/o no relacionados

- Organización débil o al azar

- Estructura incorrecta y/ poco efectiva

- Lenguaje incorrecto y/ poco efectivo

- Errores en la ortografía, puntuación y uso de mayúsculas son desproporcionados a la longitud y complejidad

\section{Aprendiz}

- Alguna evidencia de comunicación con una audiencia para un propósito específico; algunos lapsos en el foco

- Idea de desarrollo poco elaborada; detalles poco elaborados y/o repetitivos

- Lapsos en organización y/o cohesión

- Estructura oracional simple y/o torpe

- Lenguaje simple y/o impreciso

- Algunos errores en ortografía, puntuación y uso de mayúsculas que no interfieren con la comunicación

\section{Competente}

- Focalizado en un propósito; se comunica con una audiencia; evidencia de voz y/o tono apropiado

- Profundidad de desarrollo de ideas apoyada con detalles elaborados y relevantes

- Organización lógica y coherente

- Estructura controlada y variada

- Lenguaje aceptable y efectivo 
- Pocos errores en ortografía, puntuación y uso de mayúsculas en relación a la longitud y complejidad

\section{Distinguido}

- Establece un propósito y mantiene un foco claro; fuerte conciencia de audiencia; evidencia de voz distintiva y/o tono apropiado

- Profundidad y complejidad de ideas apoyada por detalles sólidos, interesantes y/o pertinentes; evidencia de análisis, reflexión, profundidad de pensamiento

- Organización cuidadosa y/o sutil

- Variedad de estructura y longitud oracional intensifica el efecto

- Lenguaje preciso y/o rico

- Control de la ortografía, puntuación y uso de mayúsculas. 


\section{Anexo 3}

Seguramente, alguien alguna vez te ha contado un cuento o has leído alguno. En esta ocasión, queremos que tú escribas tu propio cuento, el cual será llevado a padres y niños de otro país que no tienen la posibilidad de escuchar o de leer cuentos como tú. Te damos algunas sugerencias para que inventes tu cuento. Si no te gustan estas sugerencias, puedes crear el tuyo propio con tu imaginación:

Sugerencias:

1. un caballo salvaje

2. niños que podían volar

3. una caja de cuentos

4. hormiguitas

5. superhéroes

6. un programa de TV

7. una película

8. las brujas y los magos

9. los duendes

10. las ciudades perdidas

11. los payasos

12. los extraterrestres

13. lo que pasó en un paseo

14. mis mascotas

15. mis dibujos animados favoritos

Las fotografías que puedes ver en el telón también pueden servirte como fuente de inspiración para tu cuento. 